\title{
Carita Paradis*
}

\section{Compromiser - a notional paradigm}

\begin{abstract}
On the basis of an investigation of the lexical forms quite, rather, fairly, and pretty in contemporary spoken British English, I postulate that these lexical items form a notional paradigm of compromiser within the category of degree modifiers. Compromisers are cognitive synonyms that occupy the middle of an abstract intensity scale, approximating a mean degree of another word, eg quite / rather / fairly / pretty dirty. They are all polysemous and poly-functional words, whose meanings are determined by a crucial semantic trait 'to a moderate degree' on the paradigmatic axis, and by a semantic-syntactic, selection-licensing mechanism on the syntagmatic axis.
\end{abstract}

\section{Introduction}

This paper will be devoted to the lexical forms quite, rather, fairly, and pretty and I will postulate that they form a notional paradigm of compromiser within the category of degree modifiers. My aim is to define the paradigm of compromiser in terms of the logically necessary linguistic features that characterise them. These features are basic to the definition of quite, rather, fairly, and pretty as cognitive synonyms. The four lexical forms may, however, differ with respect to idiosyncratic collocational restrictions and attitudinal aspects, which are not logically necessary for the encoding of the message and will therefore not be regarded as relevant in the present paper (cf Cruse 1986:270-290, 1990: 396). I have examined the use of quite, rather, fairly, and pretty in the London-Lund Corpus (LLC for short) of contemporary spoken British English ${ }^{1}$.

Broadly speaking, degree modifiers are words that scale upwards on an imaginary scale of intensity, such as very and terribly, and words that

1 The LLC consists of half a million words altogether. The spoken texts represent both dialogue and monologue. Dialogue comprises private face-to-face conversation, private conversation on the telephone and public discussion. Within monologue there are both spontaneous and prepared monologues (for a more exhaustive description of the LLC, see Greenbaum \& Svartvik 1990).

* Carita Paradis

Department of English

Lund University

Lund $(S)$ 
scale downwards, such as slightly and $a$ bit. They are interesting because they are polysemous and poly-functional lexical forms, which diachronically have undergone a process of grammaticalization from proper content words to lexically bleached words of a more functional character (see Traugott 1982, Ungerer 1988, Hopper and Traugott 1993). The fact that they are lexically bleached makes them vague, context dependent, and semantically flexible. Their semantic flexibility is revealed by their disposition to occur in more than one notional paradigm, ie they are polysemous ${ }^{2}$. They are also interesting simply because they are common in speech, and because they seem to be subject to various collocational restrictions, which I am not going to discuss here.

The procedure will be as follows: I will first briefly present the paradigm typology model for the description of degree modifiers; then I will discuss the linguistic constraints that are crucial to the definition of the paradigm of compromiser; and finally I will conclude by summing it all up.

\section{Paradigm typology}

Following Nevalainen (1991:20f), I argue that a paradigm is a set-theoretical notion within a framework of cognitive semantics. Notional paradigms are formed by lexical elements which are cognitive synonyms. Lexical elements are cognitive synonyms if they share one or more central and logically necessary semantic trait, crucial to the determination of their truth-conditions, whereas they may differ with respect to peripheral traits such as idiosyncratic collocational restrictions and connotative meanings (Cruse 1986:270-285).

Intuitively, degree modifiers seem to fall into at least three different notional paradigms which can be distinguished according to the region of the scale they occupy ${ }^{3}$.

2 The polysemy pattern, ie the way the meanings of each of these four lexical items are related, can be described in the light of the grammaticalization process they have undergone. The different stages in this process are revealed in the various meanings. The meanings have been generalised and extended acrosss different domains, the ideational, the textual, and the interpersonal domains (cf Sweetser 1991: 73, Abraham 1984: 20)

3 I say "at least" three paradigms, because there might be other paradigms as well, which are conditioned differently (see Quirk et al 1985:589ff; for the terms 'booster', 'compromiser', 'diminsher', see Quirk et al 1985:590ff). 
BOOSTERS

COMPROMISERS

\section{awfully \\ terribly \\ very}

$$
\begin{aligned}
& \text { quite } \\
& \text { rather } \\
& \text { fairly } \\
& \text { pretty }
\end{aligned}
$$

DIMINISHERS

\section{slightly \\ somewhat \\ a bit}

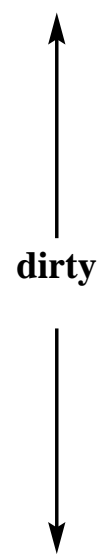

The paradigm of booster, represented by the lexical forms awfully, terribly, very, occupies the upper part of the scale according to the amplifying effect they have on the word dirty. The paradigm of diminisher, represented by slightly, somewhat, a bit, occupies the lower part of the scale according to the downtoning effect they have on dirty, and finally the paradigm of compromiser, represented by quite, rather, fairly, and pretty, occupies the middle of the scale and has the effect of approximating an assumed mean degree of dirty. Let us now take a closer look at the paradigm of compromiser, which is the topic of the present paper.

\section{The compromiser paradigm}

I work on the assumption that there is a notional paradigm of compromiser, based on the region of an intensity scale that it occupies, and that the lexical forms quite, rather, fairly, and pretty are members of that paradigm in certain linguistic contexts. Compromisers are degree modifiers, which have a compromising role in communication. They modify a scalar element and their role is to approximate an assumed mean degree of that element, which means that they can have a slight attenuating or a slight boosting effect on that element in a given context. In other words, compromisers make the application of the modified item fuzzier and less conclusive than would otherwise have been the case. Consider the following extract from the LLC (the compromiser and the modified item are given in bold). The compromising role of pretty is obvious. 
and ${ }^{\wedge} \mathrm{I}$ 'started 'working with hlim\# and ^his 'wife was \English\# and $\wedge^{\wedge}$ shle went_through some _first stage an_alyses $\left\{{ }^{\wedge}\right.$ wlith me\# $\} \#$ $\wedge$ just so I'd :get the i:dlea\# and we ^ did some sllips to'gether\# it`s $\wedge$ pretty :tledious though $\{\wedge$ \isn`t it\#\}\# (LLC 1.5. 348-353)

Pretty has the function of approximating an assumed mean degree of the scalar word tedious, and it has the function of making the application of tedious less conclusive than would otherwise be the case. Indeed, it is very difficult to pin-point the exact meaning of compromisers, not only because they are inherently vague and subjective, but also because they are lexically bleached and consequently the interpretation of them is highly sensitive to contextual factors.

In the case of compromisers, the central trait they have in common is that they all correspond to the notion 'to a moderate degree'. Cognitive synonyms such as quite, rather, fairly and pretty are thus capable of yielding sentences with the same truth-conditions, which can be diagnosed by means of entailment relations between sentences in the following way (Cruse 1986:88, 270-285):

She is quite nice

She is rather nice

She is pretty nice

She is fairly nice (but not very / slightly nice)

(but not very / slightly nice)

(but not very / slightly nice)

(but not very / slightly nice)

But the following are awkward:

?She is quite nice (but not rather / pretty/fairly nice)

?She is rather nice (but not quite / pretty / fairly nice)

?She is pretty nice (but not quite / rather / fairly nice)

?She is fairly nice (but not quite / rather / pretty nice)

To describe the linguistic factors that determine cognitive synonymy is the goal of studies in variation, and also the goal of this paper. For this purpose, I picked out all the instances of quite, rather, fairly, and pretty from the LLC, and arrived at the distribution shown in Table 1. Not all occurrences in the table are tokens of 
Table 1. The total number of quite, rather, fairly, and pretty in LLC

\begin{tabular}{lc}
\hline Lexical form & Number \\
\hline quite & 884 \\
rather & 510 \\
fairly & 122 \\
pretty & 112 \\
\hline Total & 1628 \\
\hline
\end{tabular}

compromisers. On the contrary, these lexical forms show a great deal of flexibility, and sometimes also ambiguity, with respect to their notional interpretation. Consider examples (1) to (8):

QUITE

(1) [@:] it`s ^got - [@] :quite 'high m/ountains\# . (LLC 10. 8:1. 64)

[Compromiser]

(2) be ^quite “clertain\# ^ that you :hold it very :dVefinitely _there\# (LLC 1.1.513-14)

[Maximizer]

(3) $\wedge^{\wedge} \mathrm{I} \cdot{ }^{\wedge} \mathrm{I}$ ! [len] ${ }^{\wedge} \mathrm{I}$ !stlill $\left\{{ }^{\wedge}\right.$ dlon` ${ }^{\wedge} \# \# \# \wedge^{\wedge}$ really :quVite 'know\# ${ }^{\wedge}$ whether he !hlad . 'nasty des/igns\# (LLC 2.12 1055-57)

[Equalizer]

In (1), quite is a compromiser in that it approximates an assumed mean degree of the word high. In (2) the meaning of quite comes close to that of completely and the semantic role is that of maximizing rather than compromising, and in (3) quite means 'exactly' and has what might be called an equalizing function. Alternatively, (3) is ambiguous between the equalizing and the maximizing roles, ie between 'completely' and 'exactly'. Contextual clues are important for the interpretation of ambiguous cases.

RATHER

(4) [ae] ^actually I was 'feeling rather :grlotty last w/eek\# (LLC 9.1:8. 411)

[Compromiser]

(5) ((for the 'course))—(we`re ^not 'doubting your a"! bVility to 'do it\# - but

${ }^{\wedge}$ rather your +.+ pre”! plaredness to 'do it you s/ee\# . (LLC 3.1. 529)

[Preference]

In (4) rather is a compromiser, whereas in (5) it means 'sooner' and expresses the speaker's preference of choice. 


\section{FAIRLY}

(6) [@] I ^thought I’d ‘do 'something ‘fairly slimple\# (LLC 5.8. 158)

[Compromiser]

(7) as with his $\wedge$ \{luniform\} fairly "'glVittering in the 'sun\# (LLC 10.7:2 796 [Emphasizer]

Fairly in (6) is a compromiser, whereas it is more of an emphasizer meaning 'positively' in (7) (for the term 'emphasizer, see Quirk et al 1985:583ff). In addition, there is the possible use of fairly, as a manner adverbial, meaning 'justifiably', or 'in a fair way'.This use will not be considered here at all.

\section{PRETTY}

$$
\begin{aligned}
& \text { **[@:m]**.^how are thlings\# } \\
& \text { “^loh\# . ^pr/etty !nlice /actually\#(LLC 7,2:8. 709-11) }
\end{aligned}
$$

[Compromiser]

Pretty occurs only as a compromiser, as illustrated in (8). All instances of pretty as an adjective meaning 'good-looking' are excluded from this study. Thus, examples (1) to (8) well illustrate that quite, rather, fairly and pretty (if we also consider the possible use of pretty as an adjective) are polysemous lexical forms and as such they are members not only of the paradigm of compromiser but of other paradigms as well due to both semantic and syntactic constraints. This fact makes the issue of categorisation important both from a theoretical and a methodological point of view.

Considering the various semantic roles they can take on, it is clear that pretty represents the most clear-cut case of a compromiser. Fairly is not particularly complicated either. I found just one semantically deviant example (7). It is my guess that what pretty and fairly have in common is that they have an fairly clear-cut semantic trait that is not liable to ambiguous interpretations, whereas quite and rather are more versatile due to their set-up of competing semantic traits such as 'maximizing' in (2), and 'preference' in (5), which are contextually determined.

The above examples reveal that the meanings of words like quite, rather, pretty, and fairly are only fully reflected in their context. In fact, we could go even further and say that their meanings are more or less constituted by their contextual relations. It is not possible for a speaker of English to say what these words mean when they are out of context. 
What then are the defining linguistic characteristics of compromisers? Since compromisers are dependent on features of the element they modify, it does not suffice to say that compromisers occupy the middle of an abstract scale of intensity and that they correspond to the concept 'to a moderate degree'. We also have to specify when and why they do so. Otherwise, we would have no explanation for the different interpretations of for example quite and rather in the following expressions:

(9) It was quite nice of him to tell me. ('to a moderate degree)

(10) I'm quite sure he will come.

('completely')

(11) This is a rather interesting book.

('to a moderate degree')

(12) I'd rather like to go now.

('preferably')

First, I would argue that compromisers modify another element semantically by influencing the degree of its descriptive meaning, which means that they directly interact with the item they modify, and for that reason they have to occur in a construction where they can select a scalar feature in order to obtain the appropriate interpretation (cf Allerton 1987: 20). In (9) and (11) quite and rather select a scalar feature in nice and interesting respectively. This selection of a scalar feature yields the compromiser interpretation. In (10) quite selects a limit feature, at least potentially, which yields a maximizing interpretation. Quite is then not a member of the compromiser paradigm, but instead a member of another paradigm, which is associated with a limit feature. Yet, it should be noted that the word sure is potentially ambiguous between a limit interpretation and a scalar interpretation and so is quite, and such constellations have to be disambiguated by prosody or by contextual clues, which I will not go into in this paper. If we replace quite by pretty in the same expression ('I am pretty sure'), pretty, which is a clear-cut compromiser, can only identify the scalar feature of sure; the opposite is true if we replace quite with absolutely, ('I am absolutely sure') which is a clear-cut maximizing word, allowing only the limit feature of sure to be activated.

In (12) rather does not apply to a specific element in the sentence and is consequently incapable of selecting a feature in such an element. Rather is not a word modifier in the traditional sense at all, but it modifies the whole proposition. It is thus a sentence modifier that has the function of relating the content of the whole sentence to the rest of the 
discourse in a given way (cf Nevalainen 1991:6). My claim is that the compromiser interpretation of quite, rather, fairly and pretty is due to selectional restrictions of a semantic nature on the syntagmatic axis.

Then, following Cruse (1986:103ff), I would claim that these selectional restrictions are bi-directional, ie the two constituents, the compromiser and the semantic head, exert semantic pressure on each other. This semantic pressure is provided by the availability of a scalar feature in the semantic head and the ability of the compromiser to identify it. There are thus two conditions that have to be satisfied if quite, rather, fairly and pretty are to be interpreted as compromisers. These are that the semantic head has to have a scalar feature that can be selected by the compromiser, and that the compromiser occurs in a position immediately in front of and adjacent to its semantic head, so that it can identify the scalar feature in the semantic head and so that the interpretation of the compromiser can be licensed by this scalar feature (for the term 'licensing', see Travis 1988: 289). Compromisers are thus semantically licensed to occur in a certain syntactic position. In consequence, this semantic-syntactic licensing mechanism restricts the notional space of the polysemous lexical forms quite, rather, fairly, and pretty to that of compromisers. The bi-directionality lies in the identification of a scalar feature in the modified item by the compromiser, ie a selection from left to right, and the licensing of the compromiser by the modified item from right to left.

It follows that two criteria must be fulfilled for the inclusion of a certain lexical form in the paradigm of compromiser. The first criterion applies to the paradigmatic axis, and the second applies to the syntagmatic axis, and the two are interrelated both semantically and syntactically by a bi-directional selective-licensing mechanism.

\section{PARADIGMATICALLY}

compromisers occupy the middle of an intensity scale ranging from amplification to downtoning. Compromisers are cognitive synonyms which means that they are variant lexical forms sharing the same central semantic trait 'to a moderate degree'.

\section{SYNTAGMATICALLY}

compromisers are semantic selectors in that they identify and select a scalar feature in the semantic head. Inversely, compromisers are semantico-syntactically licensed by the head. It is in effect this selectionlicensing mechanism that restricts the notional space of the compromiser. 
Given this definition of the compromiser paradigm, I will now return to my table concerning the distribution of the lexical forms quite, rather, pretty, and fairly in the LLC. However, I will now add a column for the distribution of compromisers, as shown in Table 2. The table shows that only half of the occurrences of quite were

Table 2. The distribution of all tokens of quite, rather, fairly, and pretty, and the distribution of them as compromisers in LLC.

\begin{tabular}{lcc}
\hline Lexical form & All tokens & Compromisers \\
\hline quite & 884 & 429 \\
rather & 510 & 380 \\
fairly & 122 & 121 \\
pretty & 112 & 112 \\
\hline Total & 1628 & 1042 \\
\hline
\end{tabular}

compromisers, whereas approximately $3 / 4$ of the occurrences of rather were compromisers, all occurrences except one of fairly were compromisers, and all the occurrences of pretty were compromisers. Quite and rather are consequently more versatile and much more flexible with respect to their semantic role in contemporary spoken British English as represented in the London-Lund Corpus.

\section{Conclusion}

In this paper I have described the compromisers, quite, rather, fairly, and pretty within a paradigm typology model. A paradigm is a set-theoretical notion, and the members of a paradigm are cognitive synonyms. I have postulated that quite, rather, fairly, and pretty form such a notional paradigm, the compromiser paradigm, within the category of degree modifiers. Compromisers occupy the middle of an intensity scale ranging from amplification to downtoning, and they have the effect of approximating an assumed mean degree of the word they modify, eg quite / rather / fairly / pretty dirty. Obviously, there are constraints on the interpretation of these lexical forms both on the paradigmatic and on the syntagmatic axis.

Paradigmatically, the compromisers are cognitive synonyms, which means that they are variant lexical forms sharing the same central 
semantic trait 'to a moderate degree'. Syntagmatically, the interpretation of the compromisers is restricted by a bi-directional selectionlicensing mechanism. The compromiser identifies and selects a scalar feature in the semantic head. This scalar feature then in turn licenses the modifier position and makes possible a compromiser interpretation.

This view takes as basic the premise that meaning is a structure that is mentally encoded in the mind of human beings, and semantic categorisation is a question of a system of human conceptualisation (cf Jackendoff 1988, Cruse 1990) However, a characterisation of the paradigm of compromiser does not finish here. For a more comprehensive description of compromisers, aspects, such as the lexical differences between the items, their collocational properties, their syntactic properties, will have to be covered. That remains to be done.

\section{References:}

Abraham, W. (1984): Domain, domain adverbs, and the theory of metaphor. In: Papiere zur Linguistik, 30, 3-21.

Allerton, D.J. (1987): English intensifiers and their idiosyncracies. In: Language topics. Essays in honour of Michael Halliday. eds. R. Steele and T. Threadgold. vol. 2, 1531. Amsterdam: John Benjamin.

Cruse, D.A. (1986): Lexical Semantics. Cambridge: Cambridge University Press.

Cruse, D.A. (1990): Prototype theory and lexical semantics. In: Meanings and prototypes:studies in linguistic categorization. ed. by Savas L. Tsohatzidis. London and New York: Routledge.

Greenbaum, S \& J.Svartvik (1990): The London-Lund Corpus of spoken English. ed by J. Svartvik. Lund Studies in English 82: Lund University Press.

Hopper, Paul J. \& Elizabeth Closs Traugott.1993. Grammaticalization. Cambridge: Cambridge University Press.

Jackendoff, Ray (1988): Conceptual Semantics. In Meaning and mental representation ed. by Umberto Eco, Marco Santambrogio, and Patrizia Violi. Bloomington and Indianapolis: Indiana University Press.

Quirk, R., S. Greenbaum, G. Leech \& J. Svartvik (1985): A comprehensive grammar of the English language. London: Longman.

Nevalainen, Terttu (1991): But, only, just; Focusing Adverbial Change in Modern English 1500-1900. Mémoires de la société néophilologique de Helsinki 51. Helsinki: Société Néophilologique.

Sweetser, E. (1991): From Etymology to Pragmatics. Cambridge: Cambridge University Press. 
Traugott, Elizabeth Closs (1982): From Propositional to Textual and Expressive Meanings: Some Semantic-pragmatic Aspects of Grammaticalization. In: Perspectives on Historical Linguistics. (Current Issues in Linguistic Theory 24) ed by W.P. Lehmann \& Y. Malkiel, 245-271. Amsterdam: John Bejamins.

Travis, L. (1988): The syntax of adverbs. Mc Gill working papers in linguistics. Special issue on comparative Germanic syntax. Montreal.

Ungerer, Friedrich (1988): Syntax der englischen Adverbialen. Linguistische Arbeiten, 215, Tübingen: Max Niemeyer Verlag. 
168 